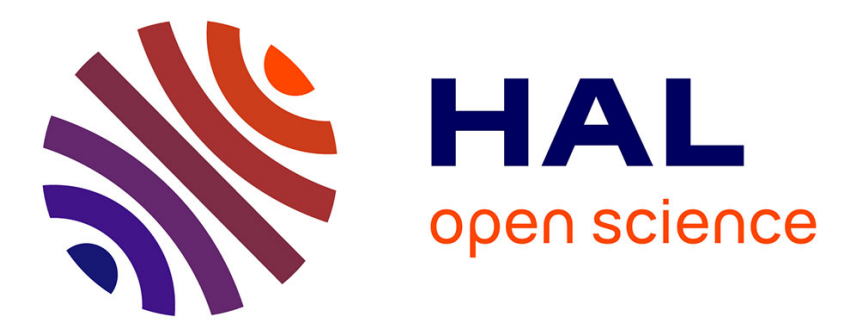

\title{
Pseudorabies virus glycoprotein B can be used to carry foot and mouth disease antigens in DNA vaccination of pigs.
}

Daniel Dory, Michelle Rémond, Véronique Béven, Roland Cariolet, Marija Backovic, Stéphan Zientara, André Jestin

\section{To cite this version:}

Daniel Dory, Michelle Rémond, Véronique Béven, Roland Cariolet, Marija Backovic, et al.. Pseudorabies virus glycoprotein B can be used to carry foot and mouth disease antigens in DNA vaccination of pigs.. Antiviral Research, 2009, 81 (3), pp.217-25. 10.1016/j.antiviral.2008.11.005 . hal-00404242

\section{HAL Id: hal-00404242 \\ https://hal-anses.archives-ouvertes.fr/hal-00404242}

Submitted on 15 Jul 2009

HAL is a multi-disciplinary open access archive for the deposit and dissemination of scientific research documents, whether they are published or not. The documents may come from teaching and research institutions in France or abroad, or from public or private research centers.
L'archive ouverte pluridisciplinaire HAL, est destinée au dépôt et à la diffusion de documents scientifiques de niveau recherche, publiés ou non, émanant des établissements d'enseignement et de recherche français ou étrangers, des laboratoires publics ou privés. 


\title{
PSEUDORABIES VIRUS GLYCOPROTEIN B CAN BE USED TO CARRY FOOT AND MOUTH DISEASE ANTIGENS IN DNA VACCINATION OF SWINE
}

\author{
Running title: anti-FMDV responses after PrV-gB / FMDV \\ BT injection
}

\author{
Daniel Dory ${ }^{\mathrm{a}}$, Michelle Rémond ${ }^{\mathrm{b}}$, Véronique Béven $^{\mathrm{a}}$, Roland Cariolet $^{\mathrm{c}}$, Marija \\ Backovic $^{d}$, Stephan Zientara ${ }^{b}$ and André Jestin ${ }^{a}$ \\ ${ }^{a}$ Viral Genetics and Biosafety Unit, French Food Safety Agency (Afssa), Fr-22440, \\ Ploufragan, France \\ ${ }^{\mathrm{b}}$ UMR 1161 (Inra-Afssa-Enva), Afssa, Fr-94703, Maisons-Alfort, France \\ ${ }^{c}$ Healthy Pigs Production and Experimentation Section, Afssa, Fr-22440, Ploufragan, France \\ ${ }^{\mathrm{d}}$ Structural Virology Unit, Institute Pasteur, 75724 Paris, France
}

*Corresponding author: Daniel Dory, Viral Genetics and Biosafety Unit, Afssa (French Food Safety Agency), BP-53, Fr-22440, Ploufragan, France

Phone: 0033296016442

Fax: 0033296016283

d.dory@afssa.fr 


\section{Abstract}

44

0

To evaluate the feasibility of using Pseudorabies Virus (PrV) glycoprotein B (gB) as a carrier of Foot and Mouth Disease Virus (FMDV) antigens in DNA immunization, FMDV B- and Tcell epitopes were inserted either between the 2 B-cell epitopes of the N-term subunit of $\operatorname{PrV}$ gB (BT-PrVgB-N term construct) or within the B-cell epitope of the C-term subunit of PrV gB (BT-PrVgB-C term construct). Two animal experiments were performed, each with 3 injections of plasmids 2 weeks apart, followed by a booster inoculation of peptides corresponding to the FMDV epitopes. Control groups of pigs were injected with plasmids encoding either PrV gB or FMDV BT, or with empty pcDNA3. The results of both assays were combined. Significant titers of FMDV neutralizing antibodies were detected after the peptides boost in groups injected with $\mathrm{BT}-\mathrm{PrVgB}-\mathrm{C}$ term. Insignificant amounts were detected in groups injected with BT-PrVgB-N term and FMDV BT constructs. PBMCs from the BT-PrVgB-N term groups, isolated after the peptide boost injection, produced IFN- $\gamma$ and IL-4 mRNAs in vitro when stimulated with FMDV peptides. This was not observed with the other groups. These results imply that $\operatorname{PrV} \mathrm{gB}$ can be used to carry FMDV antigens in a DNA vaccine.

Keywords: Foot and mouth disease virus; Pseudorabies virus glycoprotein B; B- and T-cell epitopes; carrier of antigens; DNA vaccination 


\section{Introduction}

Foot and Mouth Disease Virus (FMDV) is the etiological agent of an important disease of livestock. FMD is highly contagious and affects cloven-hoofed animals, mostly cattle, swine, sheep and goats. FMDV belongs to the Aphthovirus genus of the Picornaviridae family and is classified into 7 serotypes (Bachrach, 1968; Rodrigo and Dopazo, 1995; Sobrino et al., 2001). One strategy employed to control disease propagation consists of regular vaccination with an inactivated whole virus antigen combined with an adjuvant (Barteling and Vreeswijk, 1991; Grubman, 2005; Saiz et al., 2002) and has resulted in eradication of the disease in some parts of the world (particularly Western Europe) (Sobrino et al., 2001). Pigs were protected against experimental FMDV challenges 4 days after vaccination (Salt et al., 1998) but no antibodies were detected at this time point. A Th1/Th2 balanced immune response was characterized 14 to 21 days after emergency vaccination (Barnard et al., 2005). As these vaccines have certain drawbacks (Cox et al., 2003; Grubman and Baxt, 2004; King et al., 1981), much effort has been made to develop efficient alternative vaccines, such as proteins, peptides, replicating vectors or DNA vaccines (Grubman, 2005). In the latter case, plasmids encoding large fragments of an FMDVgenome-like P1-2A3C3D construct (Cedillo-Barron et al., 2001), VP1 (Li et al., 2007; Park et al., 2006; Xiao et al., 2007) or FMDV B and T cell epitopes (Borrego et al., 2006; Cedillo-Barron et al., 2003; Fan et al., 2007; Wong et al., 2002; Zhang et al., 2003) were tested. Considerable progress has been made to enhance DNA vaccination efficacy but at least 2 to 3 doses of plasmids still need to be injected (Borrego et al., 2006; Cedillo-Barron et al., 2001; Chen and Shao, 2006; Li et al., 2006).

In contrast, a single injection of the Pseudorabies Virus (PrV) specific DNA vaccine induced immune responses against $\mathrm{PrV}$ and clinical protection against an experimental lethal $\operatorname{PrV}$ infection (Dory et al., 2005b; Dufour et al., 2000; Gravier et al., 2007). Among the 3 PrV glycoproteins encoded by the DNA vaccine, $\operatorname{PrV} \mathrm{gB}$ is of particular interest. This is a 913- 
amino acid protein which contains a transmembrane domain and a furin cleavage site. This protein is highly immunogenic since 2 B-cell epitope sites (aa 59-126 and 214-279) have been identified in the N-term subunit and one B-cell epitope site (aa 540-734) in the C-term subunit site (Zaripov et al., 1999; Zaripov et al., 1998). Furthermore, sequences allowing PrV-gB endocytosis (aa 884-913), PrV-gB cell to cell spread (aa 824-854) and incorporation of this glycoprotein into virions (aa 854-913) have been well documented (Nixdorf et al., 2000). Thus, as PrV-gB is able to go both inside and outside cells, the opportunities for this glycoprotein to encounter an efficient immune cell may be increased.

Therefore, the aim of the present study was to determine the feasibility of using PrV-gB to carry FMDV epitopes in a DNA vaccine. The strategy differs from the one previously published for BHV-1 gB (Keil et al., 2005) in that the carried antigens are not released from $\mathrm{gB}$ but benefit from the immune properties of $\mathrm{gB}$ by staying attached to this glycoprotein. The FMDV B epitope of VP1 is reported to elicit the production of neutralizing antibodies (Francis et al., 1987). The T cell epitope of VP4 is capable of assisting a B-cell epitope when in tandem (Blanco et al., 2000). These different items i.e. the FMDV type C, isolate C-8Sc1, B-cell epitope (aa 133-156 of VP1) fused to the T-cell epitope (aa 20-34 of VP4), which have been previously evaluated in mice (Borrego et al., 2006), were here inserted into PrV-gB. The method used to insert the FMDV epitopes was therefore based on information in the literature. The protein is known to contain $3 \mathrm{~B}$ cell epitopes which means that these sites are recognized by the immune system and are therefore situated on the protein surface. Two constructs were evaluated. The first was obtained by inserting FMDV BT between the 2 Bcell epitopes of the N-term subunit of PrV-gB. The second was obtained by inserting the FMDV epitopes into the B-cell epitope of the C-term subunit of PrV-gB. The immune responses against FMDV obtained with these constructs were compared to those obtained with a plasmid encoding the FMDV B- and T-cell epitopes. As the immune potentials of these 
115 constructs are unknown, the likelihood of measuring subsequent events was maximized by 116 administering 3 injections of plasmids 2 weeks apart followed by a booster inoculation with 117 the corresponding B- and T-cell epitope peptides, 2 weeks after the last plasmids injection. 118 The immune responses against FMDV and PrV were analysed after each injection.

119 


\section{Materials and methods}

121

122

123

124

125

126

127

128

130

131

132

133

134

135

136

137

138

139

140

141

\subsection{Construction and in vitro characterization of plasmids}

The pcDNA3 plasmid encoding PrV glycoprotein gB has already been constructed, characterized and successfully used in our laboratory (Dory et al., 2005a; Dufour et al., 2000). The pGEM-based plasmids encoding the fused FMDV type C, isolate C-8Sc1, B-cell epitope (aa 133-156 of VP1) and T-cell epitope (aa 20-34 of VP4) were kindly provided by Belen Borrego (INIA, Valdeolmos, Spain). The FMDV BT construct was subcloned into the pcDNA3 expression cassette after BamHI and NotI digestions. In order to insert the FMDV BT sequence between the $2 \mathrm{~B}$-cell epitopes of the $\mathrm{N}$-term subunit of the PrV gB gene without modifying the reading frame of $\mathrm{gB}$, the BsiWI site (at the level of aa 187-189) was chosen (Fig. 1). BsiWI restriction sites were introduced on the FMDV BT insert by performing PCR on pGEM-FMDV BT with the following primers: 5'CGCATGCGTACGGCCGC3' and 5'ATTAGATCCGTACGTGGAGTT3' (BsiWI specific site is in bold and underlined). The PCR product and pcDNA3-PrV gB were digested with BsiWI (New England Biolabs) according to the manufacturer's instructions. After dephosphorylation of the digested pcDNA3-PrV gB, the digested PCR product was inserted into the PrV gB gene. The resulting plasmid was called BT-PrVgB-N term. In order to insert the FMDV BT sequence into the Bcell epitope of the C-term subunit of the $\operatorname{PrV} \mathrm{gB}$ gene without modifying the reading frame of $\mathrm{gB}$, we chose the FspAI restriction site (at the level of aa 682), which generates blunt ends. Appropriate restriction sites generating blunt ends on the FMDV BT insert were produced by performing a PCR on pGEM-FMDV BT with the following primers: 5'TGGATCCCGGGCTACGAC3'containing a SmaI restriction site (in bold and underlined) and 5'CTACATGGAGTACTGGTACTG3' containing a ScaI restriction site (in bold and underlined). The PCR product was first cloned into a TOPO-TA vector (Invitrogen). The resulting vector was then digested with $S m a I$ and $S c a I$ and the insert transferred into 
146 pcDNA3-PrV gB digested with FspAI. The resulting plasmid was called BT-PrVgB-C term.

147 Each construct was further characterized according to restriction patterns and sequencing (not 148 shown). Porcine kidney cell line 15 (PK15) was transfected with $2 \mu \mathrm{g}$ of each plasmid by

149 using lipofectamine plus transfection reagent (Invitrogen, Gaithersburg, MD, USA) according 150 to the manufacturer's instructions. Twenty-four hours after transfection, the cells were stained 151 to reveal the expression of either $\operatorname{PrV} \mathrm{gB}$ or FMDV BT. For PrV $\mathrm{gB}$, the cells were 152 successively incubated with pig PrV-specific hyperimmune antiserum, with HRP-labeled 153 rabbit anti-swine IgG at 1:1000 (Sigma, Saint-Louis, MI, USA) and with the 3-amino-9154 ethylcarbazole peroxidase substrate (Serotec Ltd, Oxford, UK) according to the 155 manufacturer's instructions (Fig. 1). For FMDV BT, the cells were successively incubated 156 with the monoclonal GB1 antibody at 1:100, with HRP-labelled rabbit anti-mouse IgG at 157 1:1000 (Dako, Trappes, France) and with the 3-amino-9-ethylcarbazole peroxidase substrate 158 (Serotec Ltd).

159 Each plasmid was individually introduced into the Escherichia coli Top10 strain, and 160 amplified and purified using the EndoFree plasmid Mega kit (Qiagen, Hilden, Germany) 161 according to the manufacturer's instructions.

162

\subsection{Animal experiments}

164 Specific pathogen-free pigs were housed and treated in accordance with local veterinary 165 office regulations (Direction des Services Vétérinaires des Côtes d'Armor, France). In the 166 first assay, 5 groups of 4 pigs weighing $26.0 \pm 0.7 \mathrm{~kg}$ at the $1^{\text {st }}$ injection were used. Group 1 167 received the $\mathrm{BT}-\mathrm{PrVgB}-\mathrm{N}$ term-encoding plasmid. Group 2 received the $\mathrm{BT}-\mathrm{PrVgB}-\mathrm{C}$ term168 encoding plasmid. Group 3, which received uncarried FMDV BT, was injected with pcDNA3-FMDV BT. Group 4 was injected with pcDNA3-PrV gB in order to evaluate the

170 immune responses against $\operatorname{PrV}$ induced by the unmodified $\operatorname{PrV}$ gB. Finally, the negative 
171 control group 5 was injected with empty pcDNA3. All plasmids were co-injected with

172 pcDNA3-GM-CSF (previously used in our laboratory (Dufour et al., 2000)) as adjuvant and

173 administered 3 times by both intramuscular (i.m.) and intradermal (i.d.) routes at 2-week

174 intervals. One $\mathrm{ml}$ of sterile saline solution containing $150 \mu \mathrm{g}$ of the plasmids of interest and

$17550 \mu \mathrm{g}$ of pcDNA3-GM-CSF were injected by i.m. route in both sides of the neck using 0.8

$176 \mathrm{~mm} \times 40 \mathrm{~mm}$ needles. $0.25 \mathrm{ml}$ of saline solution containing $150 \mu \mathrm{g}$ of plasmids of interest and

$17750 \mu \mathrm{g}$ of pcDNA3-GM-CSF were injected by i.d. route into the dorsal surface of both ears

178 using $0.45 \mathrm{~mm} \times 12 \mathrm{~mm}$ needles. The i.d. injection was controlled by (i) parallel position of

179 the needle to the ear surface, (ii) high pressure applied to the syringe to inject the solutions

180 and (iii) the transient generation of white spots. The pigs then received $100 \mu \mathrm{g}$ of the FMDV

$181 \mathrm{~T}$ cell peptide and $100 \mu \mathrm{g}$ of the FMDV B cell peptide, 2 weeks after the last plasmids

182 injection. A second assay, with 8 animals per group and 4 animals in the two control groups,

183 was carried out.

184 The pigs were carefully observed for any adverse reaction after injection. Body 185 temperature was measured daily and 4 hours after each injection. Relative daily weight gains

186 were determined (Stellmann et al., 1989) for each pig. Some pigs were sacrificed during or at

187 the end of the assays for ethical reasons. The injected areas were examined to see whether or 188 not the injection of plasmids or expression of the encoded proteins produced lesions. Other 189 organs were also examined.

190 For the antibodies determinations, sera were collected before the first plasmid

191 injection, 1 and 2 weeks after each plasmid injection and 1, 2 and 3 weeks after the peptides

192 boost. To isolate PBMCs, total blood samples were collected before the first plasmid 193 injection, 2 weeks after each plasmid injection and 1, 2 and 3 weeks after the peptides boost. 
196 FMDV neutralizing antibody assays were carried out in 96-well plates as described in the OIE

197 Manual of Standards (OIE, 2000). Serial dilutions of sera were prepared in duplicate and 50 $\mu 1$ 198 of each were added for $1 \mathrm{~h}$ to $50 \mu \mathrm{l}$ of 100 TCID $_{50}$ of the FMDV C1Noville strain. Cell 199 suspension was then added to each well and the plates were incubated at $37^{\circ} \mathrm{C}$ for 3 days. The 200 cells were fixed with formalin and stained with methylene blue. Titers were expressed as the 201 last serum dilution that inhibited viral replication in $50 \%$ of the wells.

\subsection{Determination of FMDV-specific serum antibodies.}

Anti FMDV type $\mathrm{C}$ antibodies were detected by applying a competitive Elisa test as described by Mackay DK et al (Mackay et al., 2001). Briefly, 96-well, flat-bottomed plates (Maxisorp; Nunc, Roskilde, Denmark) were coated with a rabbit anti FMDV C1 strain serum diluted in carbonate/bicarbonate buffer pH 9.6 (Sigma, Saint Louis, MO, USA). After 3 washings with PBS, the plates were incubated with FMDV antigen (C 1 Noville) diluted in PBS-tween 20 $0.05 \%$ buffer supplemented with $10 \%$ bovine serum and $5 \%$ rabbit serum (blocking buffer) for $1 \mathrm{~h}$ at $37^{\circ} \mathrm{C}$. After washings, samples of pig sera diluted $1 / 5$ in blocking buffer were added

211 in duplicate and a diluted guinea-pig anti type $\mathrm{C}$ was also added as a competitor in each well.

212 After washings and incubation with a HRP-conjugated anti guinea-pig serum, the reaction was revealed with an OPD solution (Sigma). Results were expressed as the percentage

214 inhibition of the optical density (OD) obtained with the guinea-pig serum anti type $\mathrm{C} 1$ in the 215 antigen control well.

\subsection{PrV neutralizing antibodies (NAb)}

219 After complement inactivation (30 minutes at $56^{\circ} \mathrm{C}$ ), $50 \mu \mathrm{L}$ of 2 -fold dilutions of serum were incubated with $50 \mu \mathrm{L}$ of $100 \mathrm{TCID}_{50}$ of NIA3 PrV strain in $5 \% \mathrm{CO}_{2}$ in 96 -well plates for $1 \mathrm{~h}$ at 
$37^{\circ} \mathrm{C} .150 \mu \mathrm{L}$ of PK15 cells $\left(2.25 \times 10^{4}\right.$ cells $\left./ 150 \mu \mathrm{L}\right)$ were then added and incubated in $5 \%$

$222 \mathrm{CO}_{2}$ for 5 days at $37^{\circ} \mathrm{C}$.

223 NAb titers were expressed as the highest serum dilution inhibiting the cytopathic effect in 2

224 out of 4 wells containing the PrV-infected PK15 cell line.

\subsection{Determination of PrV-specific IgG1 and IgG2 serum antibodies (Ab)}

Anti-PrV IgG1 and $\operatorname{IgG} 2$ serum Ab titers were determined by indirect ELISA as previously described (Dory et al., 2005b). Briefly, Maxisorb 96-well plates (Nunc, Naperville, IL) were coated with PrV glycoproteins, kindly provided by J.C. Audonnet (Merial, Lyon, France), and successively incubated with serial threefold dilutions of serum, with mouse anti-porcine IgG1, IgG2 or total IgG (Serotec Ltd, Oxford, UK), with HRP-labeled rabbit anti-mouse IgG 232 (Jackson Laboratories, West Grove, Pennsylvania, USA) and finally with the peroxidase substrate tetramethyl benzidine (Pierce, Rockford, IL, USA). The enzyme reaction was then stopped by adding sulfuric acid. The ODs were measured at $450 \mathrm{~nm}$. IgG1 and IgG2 titers $\left(\log _{10}\right)$ were obtained from the highest dilution that gave a higher OD value than the threefold OD of a control serum from non-vaccinated and non-infected pigs.

2.7 Quantification of porcine IFN- $\gamma$ and interleukin 4 (IL-4) mRNA produced by stimulated Peripheral Blood Mononuclear Cells (PBMC)

241 PBMC were isolated from blood collected before plasmid injection, 2 weeks after each 242 plasmid injection and 1,2 and 3 weeks after the peptides boost. PBMC were either incubated 243 in vitro for 16 hours with PrV strain NIA3 (multiplicity of infection: 1), with 5 ng of FMDV

$244 \mathrm{~T}$ cell and B cell peptides, or with the RPMI culture medium alone. PBMC total RNA was 245 isolated using the 96 RNEAsy kit (Qiagen, Hilden, Germany). Porcine IFN- $\gamma$ and porcine IL-4 
246 mRNA expressions were determined by quantitative real-time polymerase chain reaction 247 (PCR) using primers, probes and PCR conditions as previously described (Dory et al., 2005a). 248 Cytokine mRNA and $\beta$-actin mRNA threshold cycles $(\mathrm{Ct})$ were determined simultaneously 249 for each sample and the relative quantities determined according to User Bulletin number 2, 250 ABI PRISM 7700 Sequence Detection System (Applied Biosystems). The amount of cytokine 251 mRNA was standardized with the internal $\beta$-actin mRNA reference $(\Delta \mathrm{Ct}=$ cytokine $\mathrm{Ct}-\beta$ 252 actin $\mathrm{Ct})$ and quantified in relation to the non-stimulated sample $(\Delta \Delta \mathrm{Ct}=\Delta \mathrm{Ct}$ of the 253 stimulated sample - $\Delta \mathrm{Ct}$ of the non-stimulated sample) according to equation $2^{-\Delta \Delta \mathrm{Ct}}$.

\section{$255 \quad 2.8$ Statistical analysis}

256 The data were analysed using the nonparametric Mann-Whitney test (Mann and Whitney, 257 1947) included in the Systat 9 software (Systat Software, Inc., Point Richmond, CA, USA). 258 This test was applied because the generated data were few in number, did not present a 259 normal distribution and consisted of unpaired quantitative data.

260 The limit of significance was 0.05 for all comparisons. 


\section{Results}

\subsection{Constructs}

Two plasmid constructs encoding PrV-gB/FMDV BT were obtained. Porcine PK15 cells transfected with each construct were stained with a pig PrV hyper-immune serum and an antibody directed against the B cell epitope of the FMDV used here (GB1) (Fig. 1). Each PrV-gB based construct was detected by the PrV hyperimmune serum. Cells transfected with the FMDV BT encoding plasmid were not detected by the GB1 anti-FMDV monoclonal antibody, whereas under the same experimental conditions both PrV gB / FMDV BT chimeric constructs were detected.

\subsection{Induction of immune responses against FMDV in pigs}

The plasmids were injected by i.m. and i.d. routes 3 times at 2 -week intervals. Two weeks after the last injection, individual FMDV $\mathrm{B}$ and $\mathrm{T}$ cell peptides were injected by the same routes. The different injections were well tolerated. The animals grew normally and gained approximately $1 \mathrm{~kg}$ per day in all groups in both assays. No fever peaks were observed 4 hours after any of the injections or during any of the daily measurements, except in 1 pig in the BT-PrVgB-N term group of the $1^{\text {st }}$ assay which had a body temperature of $40.3^{\circ} \mathrm{C}, 72$ hours after the $3^{\text {rd }}$ injection of the plasmids. This body temperature had returned to normal by the next day. Several pigs in the second assay had to be euthanized for reasons unrelated to immunization. One pig in the BT-PrVgB-N term group broke a hoof and had to be sacrificed after the $3^{\text {rd }}$ injection. One pig in the FMDV-BT group walked with a limp and was sacrificed after the second injection and another, presenting a rectal prolapse, was euthanized one week after the peptides injection. Finally, one aggressive pig in the group injected with emptypcDNA3 was euthanized after the peptides injection. 
Experiments 1 and 2 were combined to determine the induction of immune responses, and the average and standard deviation values were determined for each group. Insignificant amounts of FMDV neutralizing antibodies were first detected 2 weeks after the second injection of plasmids in the BT-PrVgB-C term group (Fig. 2). Statistically significant titers were only observed in this group 1 and 3 weeks after the FMDV B and T peptides boost $(p<0.05)$. NAb were also detected in the BT-PrV gB-C term and FMDV BT groups but the titers, in all cases, were not statistically significant. Furthermore, NAb production in the FMDV BT group was transient and could no longer be detected 3 weeks after the peptides boost, whereas it was still observed in the BT-PrVgB-C term injected group. FMDV-specific antibodies were found at the limit of detection in sera from 3 pigs in the BT-PrVgB-N term and in 2 out of 12 pigs in the BT-PrVgB-C term injected groups. These antibodies were not detected in any of the other groups.

IFN- $\gamma$ has several immunoregulatory roles and effector functions involved in Th1- responses and IL-4 plays a key role in Th2-responses (Finkelman et al., 1988; Wood and Seow, 1996). The PBMCs isolated from all these pigs were restimulated in vitro by incubation with FMDV B and T cells peptides. Significant levels of IFN- $\gamma$ mRNA were detected after the peptides boost in the BT-PrVgB-N term injected group ( $\mathrm{p}<0.05)$ (Fig. 3). IFN- $\gamma$ mRNA was not detected in the other groups during the first assay. Significant levels were also found in the BT-PrVgB-N term group one week after the peptides boost $(\mathrm{p}<0.05)$, but production was still significantly lower than in the BT-PrVgB-C term group $(\mathrm{p}<0.05)$. All the other groups remained negative. Significant amounts of IL-4 mRNA were only detected in the BT-PrVgB-

$309 \mathrm{~N}$ term group one week after the FMDV B and T peptides boost $(\mathrm{p}<0.05)$, but not in any of 310 the other groups or in the second assay (Fig. 3).

\subsection{Induction of immune responses against $\mathrm{PrV}$ in pigs}


313 PrV neutralizing antibodies were produced in significant amounts 1 week after the third 314 injection of pcDNA3 PrV-gB (Fig. 4) and remained at a significant level until the end of the assay. Significant amounts of PrV NAb were produced in the BT-PrVgB- N term and C term

316 groups, 2 and 3 weeks after the third plasmids injection. Nevertheless, except for the BT-PrV 317 gB-N term group 3 weeks after the third injection, the NAb titers were significantly lower 318 than in the PrV gB injected group. No significant NAb production was observed in the two 319 groups that received FMDV BT / PrV gB chimeric constructs, from the fourth week after the 320 last plasmids injection. Significant amounts of PrV-specific IgG1 were first detected 1 week 321 after the second plasmids injection in the groups of pigs injected with PrV gB or BT-PrVgB$322 \mathrm{~N}$ term constructs $(\mathrm{p}<0.05)$. IgG1 production was then maintained at a significant level until 323 the end of the assay. In contrast, production in the BT-PrV gB-C term group was 324 systematically and significantly lower from the first week after the second injection until the 325 end of the assay $(\mathrm{p}<0.01)$.

326 IFN- $\gamma$ and IL-4 mRNAs production was observed in PrV-stimulated PBMCs from pigs 327 injected with PrV gB, BT-PrV gB-N term and BT-PrV gB-C term constructs from week 2 328 after the second injection to week 2 after the third injection of plasmids (p<0.05) (Fig. 5). 329 From week 1 to week 3 after the FMDV B and T peptides injection, all 3 groups produced 330 significant amounts of IFN- $\gamma$ mRNA except for the Bt-PrvV gB-C term group at weeks 2 and 331 3, the BT-PrV gB-N term group at week 2 and the PrV gB group at week 3. The same was 332 true for IL-4 mRNA production, except for the BT-PrV gB-C term group at weeks 1 and 2 333 after the peptides boost, and for the BT-PrV gB-N term group at week 2. No production of 334 IFN- $\gamma$ and IL-4 RNAs was observed in the other 2 groups throughout the assay. 


\section{Discussion}

337 The production of an efficient DNA vaccine against FMDV represents a challenge for the 338 scientific community. Such a vaccine would provide an attractive alternative to the 339 conventional inactivated FMDV vaccine which often requires 3 injections of plasmids 340 (Bergamin et al., 2007; Cedillo-Barron et al., 2001; Cedillo-Barron et al., 2003; Li et al., 341 2006). A prime-boost strategy, ( $\mathrm{Li}$ et al., 2008) using inactivated FMDV as a booster to 342 significantly improve the efficacy of FMDV DNA vaccine, has recently been published. (Li et 343 al., 2008) The results reflect the difficulty of generating a powerful DNA vaccine against 344 FMDV that confers immunity after 1 or 2 injections of plasmids, as with anti-PrV vaccination 345 (Gravier et al., 2007). Our goal in this study was to see if the glycoprotein B of PrV could serve as a carrier of FMDV antigens in a DNA vaccine. This glycoprotein was selected

347 because it is already used in a successful one-shot DNA vaccine combination against PrV348 infection in swine (Dory et al., 2005b; Dufour et al., 2000; Gravier et al., 2007). It is also an 349 immunogenic protein (Zaripov et al., 1999; Zaripov et al., 1998) associated with functional 350 domains that enable it to be internalized and to go outside the cell (Nixdorf et al., 2000). It might therefore be possible to take advantage of these characteristics to carry and present 352 foreign antigens. A modified $\mathrm{gB}$ of Bovine Herpesvirus 1 (BHV-1) was recently used to transport foreign proteins (Keil et al., 2005). The transport and release of foreign proteins

354 inserted between the furin sites, was in fact facilitated by inserting a second furin cleavage 355 site into this glycoprotein. The concept in the present study is different since gB is expected not only to transport, but also to present foreign antigens. FMDV B and T cell epitopes have

357 already been tested in DNA vaccines or recombinant vaccines to immunize mice or pigs 358 against FMDV. When mice were injected 3 times with a plasmid encoding these epitopes, no 359 neutralizing antibodies were produced and no viremia was present in half of them post360 challenge (Borrego et al., 2006). Fusion of these epitopes to a signal peptide produced NAb in 
1 out of 4 mice. Co-injection of the fungus Agaricus blazei murill (Chen and Shao, 2006) or

362 fusion to swine IgG (Wong et al., 2002) were shown to enhance DNA vaccination against

363 FMDV in mice or pigs, respectively. Finally, the titers of neutralizing antibodies in pigs

364 injected twice with a recombinant adenovirus expressing FMDV B and T cell epitopes were 365 between 4 and 16, and 3 out of 5 pigs were protected (Du et al., 2007). These small FMDV B 366 and $\mathrm{T}$ cell epitopes were thus able to induce immunization and/or protection against FMDV, 367 even though the induced humoral immune responses were low or undetectable. In our carrier 368 study, 1 FMDV B-cell epitope (aa 133-156 of VP1) fused with 1 FMDV T-cell epitope (aa 20-34 of VP4) (Borrego et al., 2006) was inserted at 2 different sites on PrV-gB. The insertion 370 strategy was based on the knowledge gained from the functional studies of the B-cell epitopes 371 in PrV.

372 The three-dimensional structure of $\operatorname{PrV} \mathrm{gB}$ has not been determined, but the X-ray structure 373 of gB ectodomain from Herpes simplex virus 1 (HSV-1) is available (Heldwein et al., 2006). 374 PrV and HSV-1 gB share 50\% identity, and the high sequence conservation strongly suggests 375 that the PrV gB adopts a structure similar to the one reported for HSV-1. FMDV-BT was 376 inserted in PrV-gB between the two B-cell epitopes located close to the N-terminus of $\mathrm{gB}$ 377 (BT-PrV gB-N term), and in the B-cell epitope located in the region preceding C-terminus 378 (BT-PrV gB-C term). The residues in HSV-1 gB, which correspond to the FMDV-BT 379 insertion sites in $\operatorname{PrV} \mathrm{gB}$, were identified from the alignment of the PrV and HSV-1 gB 380 sequences. The locations of the PrV insertion sites were then mapped on the HSV $-1 \mathrm{gB}$ 381 structure as shown in Figure 6. For the BT-PrV gB-N term construct, the corresponding HSV$3821 \mathrm{gB}$ insertion site, residue Y179, is part of the fusion loop of HSV-1 gB. Fusion loops are 383 sequences rich in hydrophobic residues and are typically buried within the protein or in a 384 membrane, suggesting that the N-terminal FMDV-BT epitope may not be fully exposed in 385 PrV-gB. The limited accessibility of the epitope in BT-PrV gB-N term could be one of causes 
of the inefficient recognition by immune system and low antibody titers. For the BT-PrV gB-

387 C term construct, the homologous insertion site in HSV-1 gB is residue H657, which is 388 located in an exposed beta-strand of domain IV. Based on the HSV-1 gB structure, the C389 terminal FMDV-BT epitope would likely localize to the surface of the protein, consistent with 390 its availability for recognition by immune system.

391 The results presented here show that FMDV-BT epitopes could not be detected in vitro by the 392 GB1 monoclonal antibody unless they were carried by PrV-gB. In fact, positively stained 393 cells could be visualised after transfection by either one of the PrV-gB constructs carrying the FMDV-BT epitope. Moreover, PrV-gB was strongly expressed and detected when a pig

395 PrV-hyperimmune serum was used. This implies that multiple epitopes were recognized, whether they were near to the insertion sites or not, suggesting that some of them were not perturbed by the insertion. These findings demonstrate that the concept of $\operatorname{PrV}-\mathrm{gB}$ as a carrier of FMDV epitopes is feasible, at least in vitro. The immunization potentials of our constructs were evaluated after each of the 3 plasmids injections, as in other studies of DNA vaccination against FMDV. A FMDV peptides boost was then added to observe the production of immune responses against FMDV. The two assays (12 pigs per BT-PrV gB-C term, BT-PrV gB-N term and BT groups or 8 pigs per PrV gB and empty pcDNA3 groups in total) were combined and the averages of the two assays are presented. Significant induction of immune responses against FMDV were observed only after the FMDV B and T peptides boost in the groups primed with plasmids encoding chimeric PrV gB / FMDV BT constructs. This was not observed in the groups that were 3 times injected with empty plasmids or plasmids encoding PrV $\mathrm{gB}$ before injection of FMDV $\mathrm{B}$ and $\mathrm{T}$ peptides. In fact, in these last cases pigs received FMDV antigens only once. FMDV-specific serum antibodies were faintly detected in 5 of the 24 pigs that received the FMDV BT / PrV-gB constructs. No specific antibodies were detected in any of the other groups. Significant NAb production against FMDV was only 
411 found in the BT-PrVgB-C term construct groups. Non-significant production was detected in 412 the BT-PrV gB-N term group. Although less NAb was produced than with DNA vaccines 413 containing larger FMDV constructs, such as P1-2A3C3D (Cedillo-Barron et al., 2001), the 414 amounts were similar to previous studies with these small epitopes. Borrego et al. found that 415 only 1 out of 31 mice produced NAb after 3 injections of DNA vaccines encoding FMDV B 416 and T cell epitopes (Borrego et al., 2006). Pigs injected twice with rAdV expressing FMDV 417 BT and GM-CSF produced NAb titers between 4 and 16 (Du et al., 2007). It is important to 418 note that the B-cell epitope from the CS8 strain encoded by the vaccine differed in 2 amino 419 acids from the one obtained from the $\mathrm{C} 1$ Noville strain used in the neutralizing assay. One of 420 these amino acids is located in an area (aa 146-156) important for NAb production (Francis et 421 al., 1987). It is therefore possible that the NAb produced was less able to inhibit C1 Noville 422 during in vitro replication and that the NAb has thus been under-estimated. Furthermore, the conformations of the FMDV B and T cells may be modified by their insertion into PrV $\mathrm{gB}$, and the induction of immune responses may potentially be perturbed and decreased. Another important element in protection against FMDV is the cellular immune response (Borrego et 426 al., 2006; Sobrino et al., 2001). The BT-PrVgB-N term group seemed to favour the production of IFN- $\gamma$ mRNA (a marker of the cellular immune response) by PBMCs stimulated by FMDV B and T cell epitope peptides. Significant amounts of IL-4 mRNA (a marker of 429 induction of humoral immune responses) were detected in the same group. These results 430 suggest that both cellular and humoral immune responses were induced in this group, as in 431 efficient emergency FMDV vaccination (Barnard et al., 2005). However, the detection of 432 cytokine mRNAs does not necessarily imply that the corresponding proteins are induced. 433 These results should therefore be interpreted with caution. Barnard et al. showed that the 434 production of cytokine mRNAs by FMDV-stimulated PBMCs from FMDV vaccinated pigs 435 was correlated, in most cases, with the production of cytokines (Barnard et al., 2005). In some 
rare cases, the cytokines were not detected, whereas the mRNAs were. We can therefore be relatively confident of the results interpretation. Furthermore, the results presented here are not predictive of the ability of the constructs to protect pigs against FMDV infection. This can only be evaluated experimentally. Previous studies showed that although these FMDV B and

T cell epitopes induced no or only low titers of NAb, they were able to protect mice (Borrego

441 et al., 2006) and pigs (Du et al., 2007) against FMDV challenges. Other examples of

442 protection in the presence of low titers of FMDV NAb are reported in the literature (Sobrino 443 et al., 2001).

445 The immune responses to $\mathrm{PrV}-\mathrm{gB}$ were equivalent to those previously reported after 3 446 injections of plasmids in pigs (van Rooij et al., 2000). Insertion of the FMDV epitopes into 447 the B-cell epitope of the C-terminal region of PrV-gB, which is described as a strong 448 conformational B-cell epitope with neutralizing activity (Zaripov et al., 1998), greatly reduced 449 the humoral immune response against the PrV studied here. In contrast, insertion of the 450 FMDV epitopes between the 2 B-cell epitopes close to the N-terminus of PrV-gB, described 451 as linear epitopes inducing low antibody responses (Zaripov et al., 1998), abolished or 452 strongly reduced the production of PrV NAb, but not of IgG1 and IgG2. Our constructs could 453 be used to study the influence of modifications of certain important functional sites on the 454 induction of immune responses against FMDV and PrV i.e. the carboxy-terminal part of PrV455 gB (Nixdorf et al., 2000) PrV-gB endocytosis (aa 884-913), PrV-gB cell to cell spread (aa 456 824-854) and incorporation of this glycoprotein into virions (aa 854-913).

457 It might be possible to use these constructs to generate a DNA vaccine against FMDV and 458 PrV. The BT-PrVgB-C term construct would probably be unable to protect against $\operatorname{PrV}$ 459 infection, due to dramatic attenuation of the immune responses against $\operatorname{PrV}$, but it could be 460 useful when pigs have to be free of PrV-antibodies, as in areas where this virus has been 
461 eradicated. The BT-PrVgB-N term construct greatly attenuated the production of PrV specific $462 \mathrm{NAb}$. Its use in protecting against PrV-infection should be experimentally evaluated as 463 protection against $\mathrm{PrV}$ has already been observed in the absence of detectable induction of 464 PrV-specific NAb and with similar levels of IgG1 and IgG2 to those in the present study 465 (Gravier et al., 2007).

466

467 


\section{Conclusion}

469 In conclusion, the concept of a PrV-gB carrier of FMDV epitopes has been validated in the 470 preliminary studies presented here. The levels of NAb produced against FMDV were similar 471 to those reported in other studies involving immunization with FMDV B and T cell epitopes 472 in which no NAb (Borrego et al., 2006) or titers between 4 and 16 (Du et al., 2007) were 473 obtained. Nevertheless, strategies to improve immunization efficacy, based on co-injection of 474 adjuvants, electroporation or changing the plasmid backbone, need to be evaluated. Other 475 insertion sites on PrV-gB should also be tested, or other combinations of FMDV B- and T-cell 476 epitopes inserted (Borrego et al., 2006). The nature of the immune response against FMDV 477 depends on the site of insertion in PrV-gB. One construct, BT-PrVgB-N term, in which BT is 478 inserted between 2 PrV-gB B cell sites, seems to favor the induction of a balanced cytotoxic 479 and humoral immune response against FMDV (Barnard et al., 2005). The other construct, BT480 PrVgB-C term, in which FMDV BT is inserted in a PrV-gB B cell site, favors the induction 481 of FMDV-specific NAb. Finally, and from a more fundamental point of view, it would be 482 interesting to see how the PrV-gB sites involved in endocytosis and cell-to-cell spread 483 (Nixdorf et al., 2000) influence the induction of immune responses with these different 484 constructs. 


\section{Acknowledgments}

488

489

The authors would like to thank Dr Belen Borrego (INIA, Valdeolmos, Spain) for 490 providing the plasmid encoding FMDV B and T-cell epitopes, Dr J.C. Audonnet (Merial, 491 Lyon, France) for providing PrV glycoproteins and virulent PrV and Dr F. Lefevre (Inra, 492 Jouy-en-Josas, France) for providing the pcDNA3.1/GM-CSF plasmid. The authors are 493 grateful to B. Jan and other persons on the staff of the healthy pigs production and 494 experimentation section (Afssa, Ploufragan, France) for expert manipulation of the pigs and to 495 A. Henry (Afssa, Ploufragan, France), F. Lebreton and C. Fays (Afssa, Maisons-Alfort, 496 France) for their excellent technical assistance. This study was supported by grant QLK2-CT497 2002-01204, FMDnaVacc project, from the European Commission. 
500 Figure 1: constructs Porcine PK15 cells were transfected with pcDNA3 based plasmids 501 encoding PrV-gB, BT-PrV gB N term, BT-PrV gB C term or FMDV BT. Twenty-four hours later, cells were stained with pig PrV hyperimmune serum or anti-FMDV B epitope GD1 monoclonal antibody as described in materials and methods.

Figure 2: Anti-FMDV neutralizing antibodies Anti-FMDV neutralizing antibodies before the first injection and after each of the 3 injections of plasmids (D1, D2 and D3, indicated with arrows ) and after the peptides boost (P, indicated with an arrow). Average titers of experiments 1 and $2 \pm \mathrm{SD}$ are shown for each group indicated in the legend box .

$* \mathrm{a}: \mathrm{p}<0.05$ compared to the PrV gB and Empty pcDNA3 groups

*b: $\mathrm{p}<0.05$ compared to the PrV gB, Empty pcDNA3 and FMDV BT groups

Figure 3: IFN- $\gamma$ and IL4 mRNA relative expressions by FMDV $B$ and $T$ cell peptides stimulated PBMCs

The cells were isolated before the first injection and after each of the 3 injections of plasmids (D1, D2 and D3, indicated with arrows) and after the peptides boost (P, indicated with an arrow). The cells were than incubated with FMDV B and T peptides or with culture medium for 16 hours. IFN- $\gamma$ and IL4 mRNA relative expressions were determined. Average titers of experiments 1 and $2 \pm \mathrm{SD}$ are shown for each group indicated in the legend box .

*a: $\mathrm{p}<0.05$ compared to the PrV gB and Empty pcDNA3 groups

$* \mathrm{~b}: \mathrm{p}<0.05$ compared to all the other groups

$* \mathrm{c}: \mathrm{p}<0.05$ compared to the PrV gB, FMDV BT and Empty pcDNA3 groups

$* \mathrm{~d}: \mathrm{p}<0.05$ compared to the PrV gB, BT-PrV gB-N term and Empty pcDNA3 groups

\section{Figure 4: Anti-PrV neutralizing, IgG1 and IgG2 antibodies production.}

Sera from pigs in both assays were collected before the first injection and after each of the 3 injections of plasmids (D1, D2 and D3, indicated with arrows) and after the peptides boost (P, indicated with an arrow). Average titers of experiments 1 and $2 \pm$ SD are shown for each group indicated in the legend box .

$* \mathrm{a}: \mathrm{p}<0.05$ compared to all the other groups

*b: $\mathrm{p}<0.05$ compared to the BT-PrV gB-C term, FMDV BT and Empty pcDNA3 groups*c: $\mathrm{p}<0.05$ compared to the PrV gB, FMDV BT and Empty pcDNA3 groups

$* *: \mathrm{p}<0.01$ compared to the PrV gB and BT-PrV gB-N term groups

\section{Figure 5: IFN- $\gamma$ and IL4 mRNA relative expressions by PrV stimulated PBMCs}

The cells were isolated before the first injection and after each of the 3 injections of plasmids (D1, D2 and D3, indicated with arrows) and after the peptides boost (P, indicated with an arrow). The cells were than incubated with live PrV or with culture medium for 16 hours. IFN- $\gamma$ and IL4 mRNA relative expressions were determined. Average titers of experiments 1 and $2 \pm \mathrm{SD}$ are shown for each group indicated in the legend box.

$* \mathrm{p}<0.05$ compared to the FMDV BT and Empty pcDNA3 groups

Figure 6: Location of the PrV gB FMDV epitope insertion sites mapped on the structure of HSV-1 gB. A) Ectodomains of HSV-1 gB form trimers. Each monomer is colored as blue, green or red (left panel), and a space-filled model of the gB trimeric surface is shown on the right. Y167 and H657 are the HSV-1 residues that correspond to the insertion sites of the 
547 FMDV epitopes in PrV gB. HSV-1 gB fusion loops, which are the residues proposed to insert 548 into the target membrane during fusion, are marked. B, C) Only domains I and IV, 549 respectively, are shown for clarity, and insertion sites Y167 and H657 are labelled. Residue 550 Y167, which would correspond to the N-term FMDV epitope insertion, seems less accessible 551 than the fully exposed H657, which is analogous to the position where the C-term FMDV 552 epitope was added. This suggests that the latter position might be a better insertion target. 
Bachrach, H.L., 1968. Foot-and-mouth disease. Annu. Rev. Microbiol. 22, 201-244.

Barnard, A.L., Arriens, A., Cox, S., Barnett, P., Kristensen, B., Summerfield, A., McCullough, K.C., 2005. Immune response characteristics following emergency vaccination of pigs against foot-and-mouth disease. Vaccine 23, 1037-1047.

Barteling, S.J., Vreeswijk, J., 1991. Developments in foot-and-mouth disease vaccines. Vaccine 9, 75-88.

Bergamin, F., Saurer, L., Neuhaus, V., McCullough, K.C., Summerfield, A., 2007. Porcine Bcell activating factor promotes anti-FMDV antibodies in vitro but not in vivo after DNA vaccination of pigs. Vet. Immunol. Immunopathol. 120, 115-123.

Blanco, E., McCullough, K.C., Summerfield, A., Fiorini, J., Andreu, D., Chiva, C., Borras, E., Barnett, P., Sobrino, F., 2000. Interspecies major histocompatibility complexrestricted Th cell epitope on foot-and-mouth disease virus capsid protein VP4. J. Virol. 74, 4902-4907.

Borrego, B., Fernandez-Pacheco, P., Ganges, L., Domenech, N., Fernandez-Borges, N., Sobrino, F., Rodriguez, F., 2006. DNA vaccines expressing B and T cell epitopes can protect mice from FMDV infection in the absence of specific humoral responses. Vaccine 24, 3889-3899.

Cedillo-Barron, L., Foster-Cuevas, M., Belsham, G.J., Lefevre, F., Parkhouse, R.M., 2001. Induction of a protective response in swine vaccinated with DNA encoding foot-andmouth disease virus empty capsid proteins and the 3D RNA polymerase. J. Gen. Virol. 82, 1713-1724.

Cedillo-Barron, L., Foster-Cuevas, M., Cook, A., Gutierrez-Castaneda, B., Kollnberger, S., Lefevre, F., Parkhouse, R.M., 2003. Immunogenicity of plasmids encoding T and B cell epitopes of foot-and-mouth disease virus (FMDV) in swine. Vaccine 21, 42614269.

Chen, L., Shao, H., 2006. Extract from Agaricus blazei Murill can enhance immune responses elicited by DNA vaccine against foot-and-mouth disease. Vet. Immunol. Immunopathol. 109, 177-182.

Cox, S.J., Aggarwal, N., Statham, R.J., Barnett, P.V., 2003. Longevity of antibody and cytokine responses following vaccination with high potency emergency FMD vaccines. Vaccine 21, 1336-1347.

Dory, D., Béven, V., Torché, A.M., Bougeard, S., Cariolet, R., Jestin, A., 2005a. CpG motif in ATCGAT hexamer improves DNA-vaccine efficiency against lethal Pseudorabies virus infection in pigs. Vaccine 23, 4532-4540.

Dory, D., Torché, A.M., Béven, V., Blanchard, P., Loizel, C., Cariolet, R., Jestin, A., 2005 b. Effective protection of pigs against lethal Pseudorabies virus infection after a single injection of low-dose Sindbis-derived plasmids encoding $\operatorname{PrV} \mathrm{gB}, \mathrm{gC}$ and $\mathrm{gD}$ glycoproteins. Vaccine 23, 3483-3491.

Du, Y., Jiang, P., Li, Y., He, H., Jiang, W., Wang, X., Hong, W., 2007. Immune responses of two recombinant adenoviruses expressing VP1 antigens of FMDV fused with porcine granulocyte macrophage colony-stimulating factor. Vaccine 25, 8209-8219.

Dufour, V., Chevallier, S., Cariolet, R., Somasundaram, S., Lefêvre, F., Jestin, A., Albina, E., 2000. Induction of porcine cytokine mRNA expression after DNA immunization and pseudorabies virus infection. J. Interferon Cytokine Res. 20, 885-890.

Fan, H., Tong, T., Chen, H., Guo, A., 2007. Immunization of DNA vaccine encoding C3dVP1 fusion enhanced protective immune response against foot-and-mouth disease virus. Virus Genes 35, 347-357. 
Finkelman, F.D., Katona, I.M., Urban, J.F., Jr., Holmes, J., Ohara, J., Tung, A.S., Sample, J. V., Paul, W.E., 1988. IL-4 is required to generate and sustain in vivo IgE responses. J. Immunol. 141, 2335-2341.

Francis, M.J., Fry, C.M., Rowlands, D.J., Bittle, J.L., Houghten, R.A., Lerner, R.A., Brown, F., 1987. Immune response to uncoupled peptides of foot-and-mouth disease virus. Immunology 61, 1-6.

Gravier, R., Dory, D., Rodriguez, F., Bougeard, S., Beven, V., Cariolet, R., Jestin, A., 2007. Immune and protective abilities of ubiquitinated and non-ubiquitinated pseudorabies virus glycoproteins. Acta Virol. 51, 35-45.

Grubman, M.J., 2005. Development of novel strategies to control foot-and-mouth disease: marker vaccines and antivirals. Biologicals 33, 227-234.

Grubman, M.J., Baxt, B., 2004. Foot-and-mouth disease. Clin. Microbiol. Rev. 17, 465-493.

Heldwein, E.E., Lou, H., Bender, F.C., Cohen, G.H., Eisenberg, R.J., Harrison, S.C., 2006. Crystal structure of glycoprotein B from herpes simplex virus 1. Science 313, 217 220.

Keil, G.M., Hohle, C., Giesow, K., Konig, P., 2005. Engineering glycoprotein B of bovine herpesvirus 1 to function as transporter for secreted proteins: a new protein expression approach. J. Virol. 79, 791-799.

King, A.M., Underwood, B.O., McCahon, D., Newman, J.W., Brown, F., 1981. Biochemical identification of viruses causing the 1981 outbreaks of foot and mouth disease in the UK. Nature 293, 479-480.

Li, Y., Aggarwal, N., Takamatsu, H.H., Sterling, C.M., Voyce, C., Barnett, P.V., 2006. Enhancing immune responses against a plasmid DNA vaccine encoding a FMDV empty capsid from serotype O. Vaccine 24, 4602-4606.

Li, Y., Stirling, C.M., Denyer, M.S., Hamblin, P., Hutchings, G., Takamatsu, H.H., Barnett, P.V., 2008. Dramatic improvement in FMD DNA vaccine efficacy and cross-serotype antibody induction in pigs following a protein boost. Vaccine 26, 2647-2656.

Li, Y.G., Tian, F.L., Gao, F.S., Tang, X.S., Xia, C., 2007. Immune responses generated by Lactobacillus as a carrier in DNA immunization against foot-and-mouth disease virus. Vaccine 25, 902-911.

Mackay, D.K., Bulut, A.N., Rendle, T., Davidson, F., Ferris, N.P., 2001. A solid-phase competition ELISA for measuring antibody to foot-and-mouth disease virus. J. Virol. Methods 97, 33-48.

Mann, H.B., Whitney, D.R., 1947. On a test of whether one of two random variables is stochastically larger than the other. Ann. Math. Statist. 18, 50-60.

Nixdorf, R., Klupp, B.G., Karger, A., Mettenleiter, T.C., 2000. Effects of truncation of the carboxy terminus of pseudorabies virus glycoprotein B on infectivity. J. Virol. 74, 7137-7145.

OIE, 2000. OIE Manual of Standards for diagnostics tests and vaccines.

Park, J.H., Kim, S.J., Oem, J.K., Lee, K.N., Kim, Y.J., Kye, S.J., Park, J.Y., Joo, Y.S., 2006. Enhanced immune response with foot and mouth disease virus VP1 and interleukin-1 fusion genes. J. Vet. Sci. 7, 257-262.

Rodrigo, M.J., Dopazo, J., 1995. Evolutionary analysis of the picornavirus family. J. Mol. Evol. 40, 362-371.

Saiz, M., Nunez, J.I., Jimenez-Clavero, M.A., Baranowski, E., Sobrino, F., 2002. Foot-andmouth disease virus: biology and prospects for disease control. Microbes Infect. 4, 1183-1192.

Salt, J.S., Barnett, P.V., Dani, P., Williams, L., 1998. Emergency vaccination of pigs against foot-and-mouth disease: protection against disease and reduction in contact transmission. Vaccine 16, 746-754. 
Sobrino, F., Saiz, M., Jimenez-Clavero, M.A., Nunez, J.I., Rosas, M.F., Baranowski, E., Ley, V., 2001. Foot-and-mouth disease virus: a long known virus, but a current threat. Vet. Res. 32, 1-30.

Stellmann, C., Vannier, P., Chappuis, G., Brun, A., Dauvergne, M., Frageaud, D., Bugand, M., Colson, X., 1989. The potency testing of pseudorabies vaccines in pigs. A proposal for a quantitative criterion and a minimum requirement. J. Biol. Stand. 17, 17-27.

van Rooij, E.M., Haagmans, B.L., Glansbeek, H.L., de Visser, Y.E., de Bruin, M.G., Boersma, W., Bianchi, A.T., 2000. A DNA vaccine coding for glycoprotein B of pseudorabies virus induces cell-mediated immunity in pigs and reduces virus excretion early after infection. Vet. Immunol. Immunopathol. 74, 121-136.

Wong, H.T., Cheng, S.C., Sin, F.W., Chan, E.W., Sheng, Z.T., Xie, Y., 2002. A DNA vaccine against foot-and-mouth disease elicits an immune response in swine which is enhanced by co-administration with interleukin-2. Vaccine 20, 2641-2647.

Wood, P.R., Seow, H.F., 1996. T cell cytokines and disease prevention. Vet. Immunol. Immunopathol. 54, 33-44.

Xiao, C., Jin, H., Hu, Y., Kang, Y., Wang, J., Du, X., Yang, Y., She, R., Wang, B., 2007. Enhanced protective efficacy and reduced viral load of foot-and-mouth disease DNA vaccine with co-stimulatory molecules as the molecular adjuvants. Antiviral Res. 76, 11-20.

Zaripov, M.M., Morenkov, O.S., Fodor, N., Brown, A., Schmatchenko, V.V., Fodor, I., 1999. Distribution of B-cell epitopes on the pseudorabies virus glycoprotein B. J. Gen. Virol. 80, 537-541.

Zaripov, M.M., Morenkov, O.S., Siklodi, B., Barna-Vetro, I., Gyongyosi-Horvath, A., Fodor, I., 1998. Glycoprotein B of Aujeszky's disease virus: topographical epitope mapping and epitope-specific antibody response. Res. Virol. 149, 29-41.

Zhang, H.Y., Sun, S.H., Guo, Y.J., Zhou, F.J., Chen, Z.H., Lin, Y., Shi, K., 2003. Immune response in mice inoculated with plasmid DNAs containing multiple-epitopes of footand-mouth disease virus. Vaccine 21, 4704-4707. 


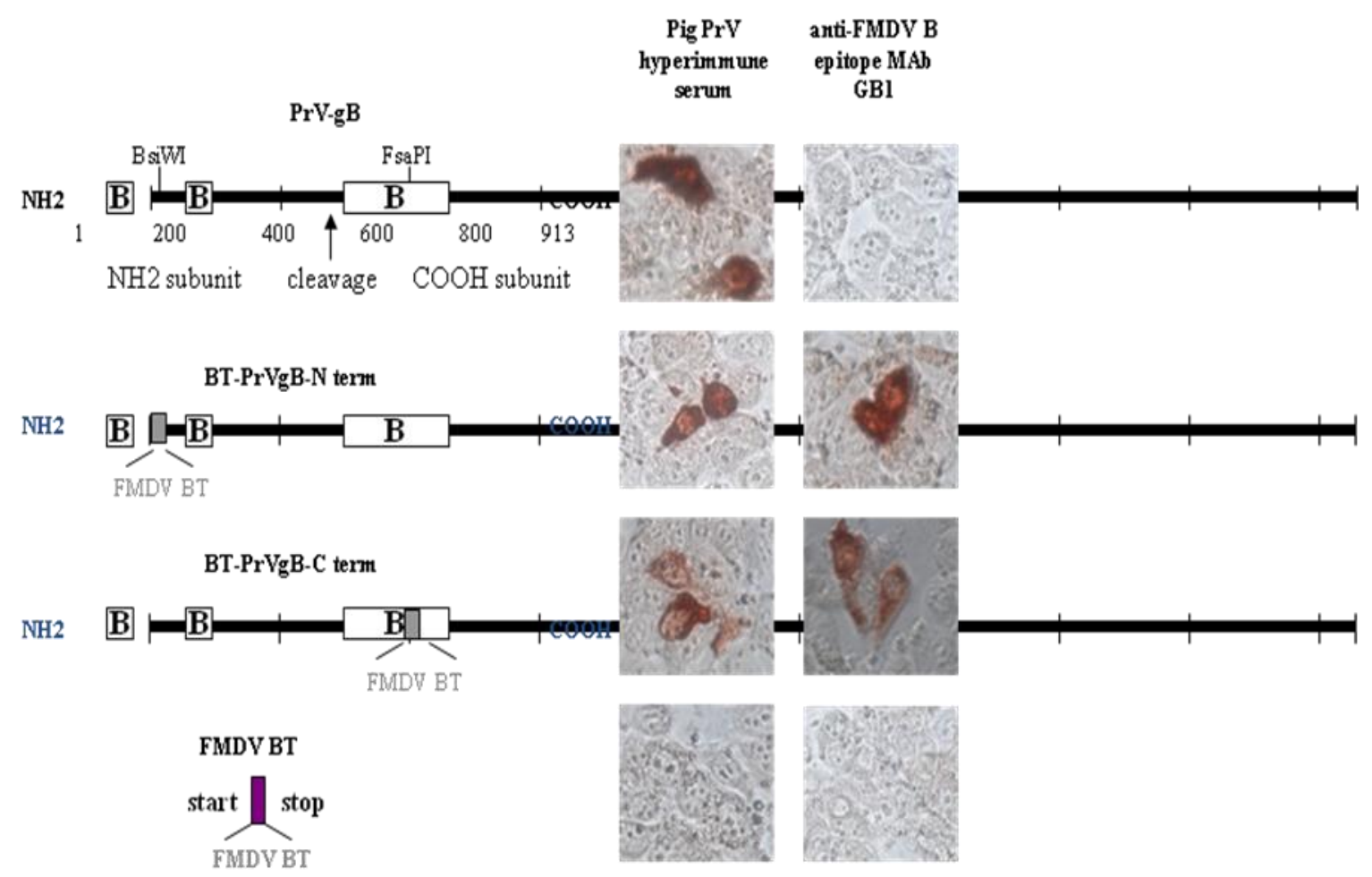

B PrV gB B cell epitope

Figure l: constructs

Porcine PK 15 cells were transfected with pcDNA3 based plasmids encoding PrV-gB, BT-PrV gB N term, BT-PrV gB C term or FMDV BT. Twenty-four hours later, cells were stained with pig PrV hyperimmune serum or antiFMDV B epitope GB1 monoclonal antibody as described in materials and methods. 


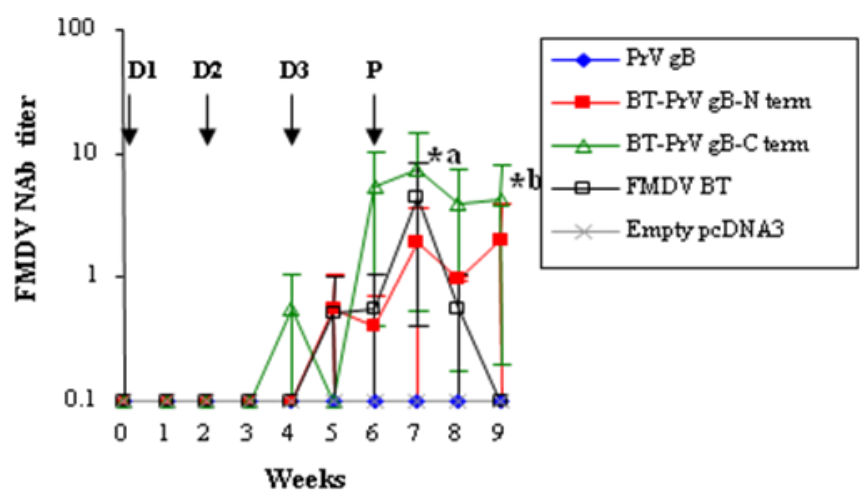

Figure 2: Anti-FMDV neutralizing antib odies

Anti-FMDV neutralizing antibodies before the first injection and after each of the 3 injections of plasmids (D 1, $\mathrm{D} 2$ and D3, indicated with arrows) and after the peptides boost (P, indicated with an arrow). Average titers of experiments 1 and $2 \pm S D$ are shown for each group indicated in the legend box 

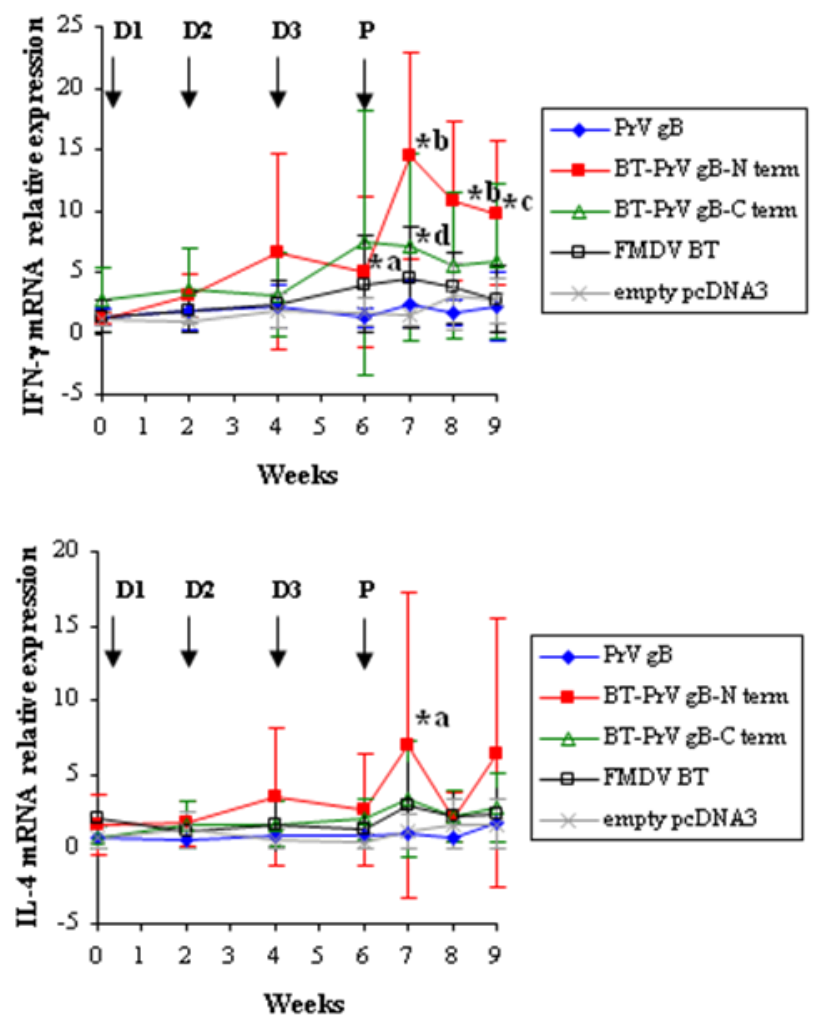

Figure 3: IFN-y and $\amalg 4$ mRNA relative expressions by FMDV B and T cell peptides stimulated PBMCs

The cells were isolated before the first injection and after each of the 3 injections of plasmids (D1, D2 and D3, indicated with arrows) and after the peptides boost ( $\mathrm{P}$, indicated with an arrow). The cells were than incubated with FMDV B and T peptides or with culture medium for 16 hours. IFN- $y$ and IL 4 mRNA relative expressions were determined. Average titers of experiments 1 and $2 \pm S D$ are shown for each group indicated in the legend box.

*a: $p<0.05$ compared to the PrV gB and Empty pcDNA3 groups

* * $p<0.05$ compared to all the other groups

*: $\mathrm{p}<0.05$ compared to the PrV gB, FMDV BT and Empty pcDNA3 groups

*d: $\mathrm{p}<0.05$ compared to the PrV gB, BT-PrV gB-N term and Empty pcDNA3 groups

693 

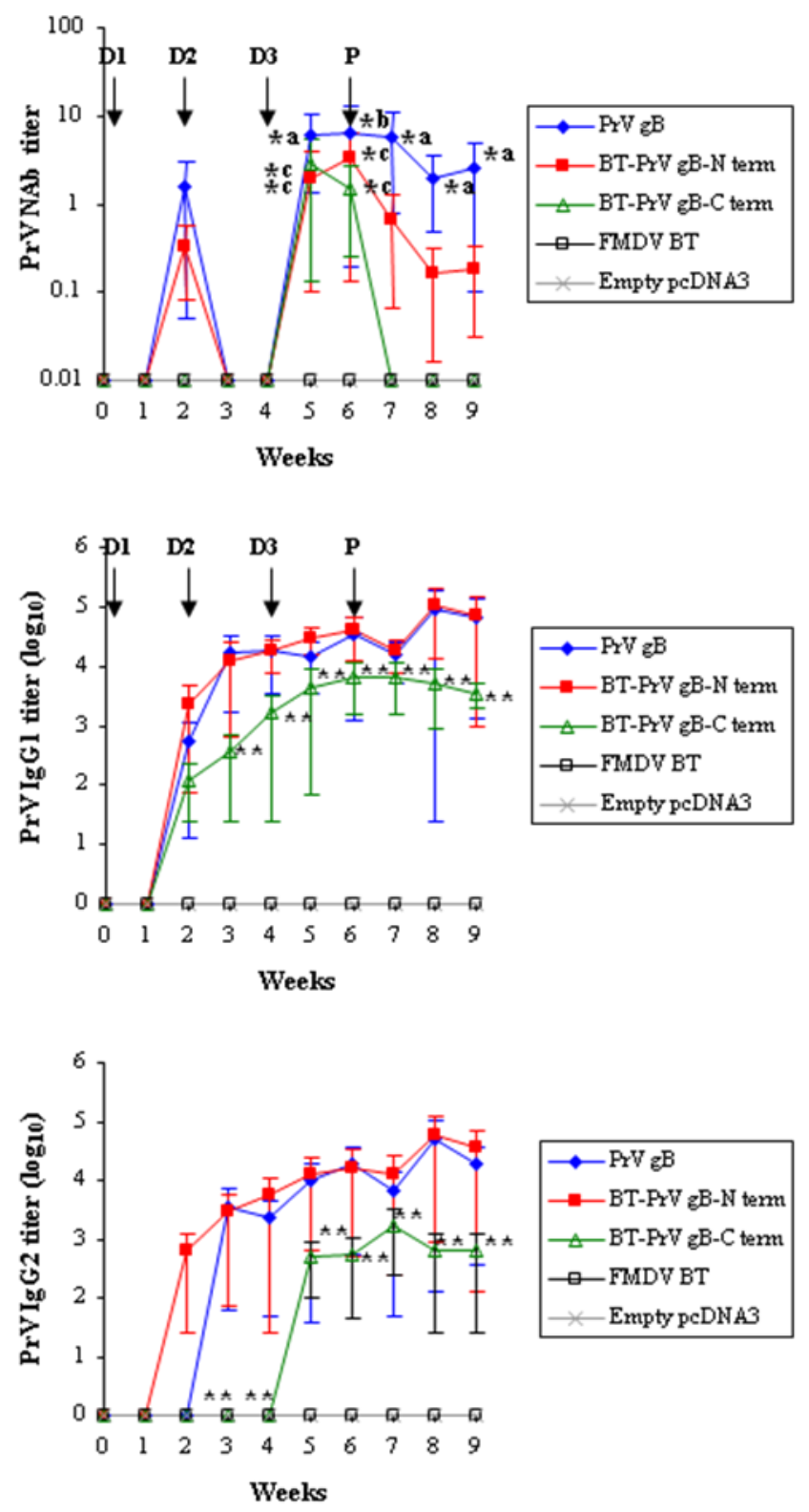

Figure 4: Anti-PrV neutr alizing, IgG1 and IgG2 antibodies production.

Sera from pigs in both assays were collected before the first injection and after each of the 3 injections of plasmids (D1, D2 and D3, indicated with arrows) and after the peptides boost (P, indicated with an arrow). Average titers of experiments 1 and $2 \pm S D$ are shown for each group indicated in the legend box.

*a: $\mathrm{p}<0.05$ compared to all the other groups

* $: p<0.05$ compared to the BT-PrV gB-C term, FMDV BT and Empty pcDNA3 groups

*: $p<0.05$ compared to the PrV gB, FMDV BT and Empty pcDNA3 groups

**: $p<0.01$ compared to the PrV gB and BT-PrV gB-N term groups 

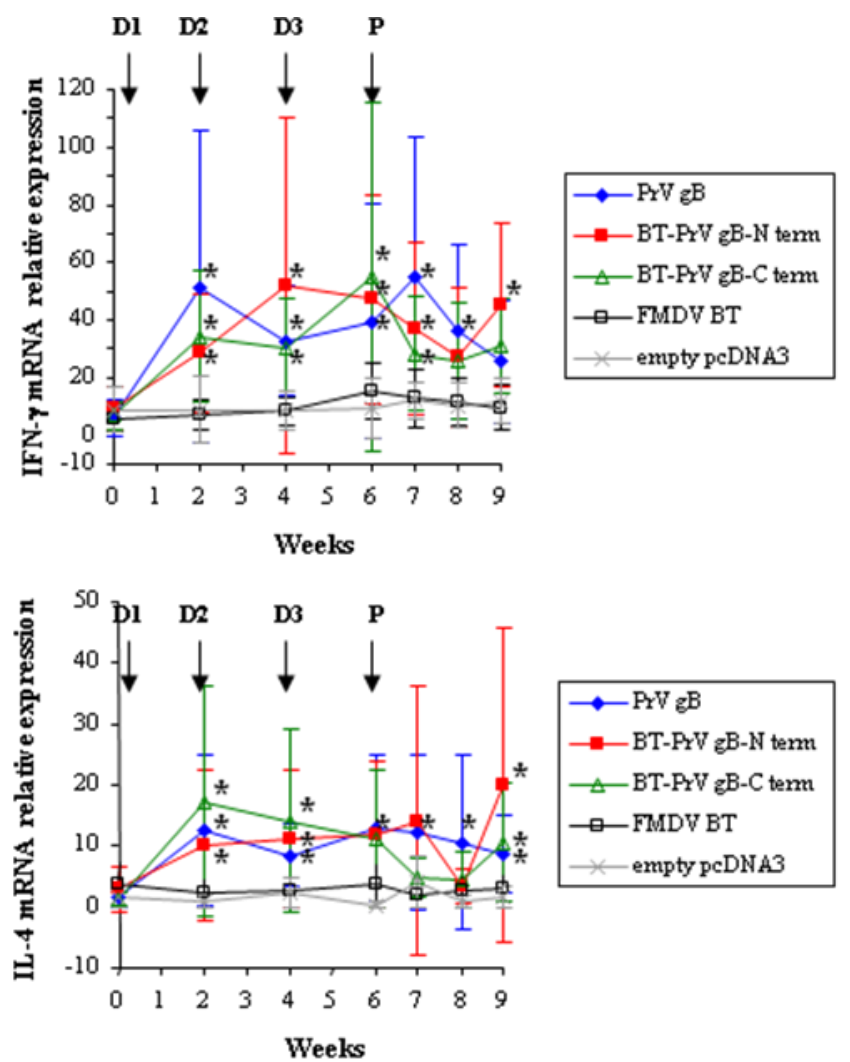

Figure 5: IFN-y and $\Pi 4$ mRNA relative expressions by PrV stimulated PBMCs

The cells were isolated before the first injection and after each of the 3 injections of plasmids (D1, D2 and D3, indicated with arrows) and after the peptides boost (P, indicated with an arrow). The cells were than incubated with live PrV or with culture medium for 16 hours. IFN- $\gamma$ and IL $4 \mathrm{mRNA}$ relative expressions were determined. Average titers of experiments 1 and $2 \pm \mathrm{SD}$ are shown for each group indicated in the legend box. 
A)

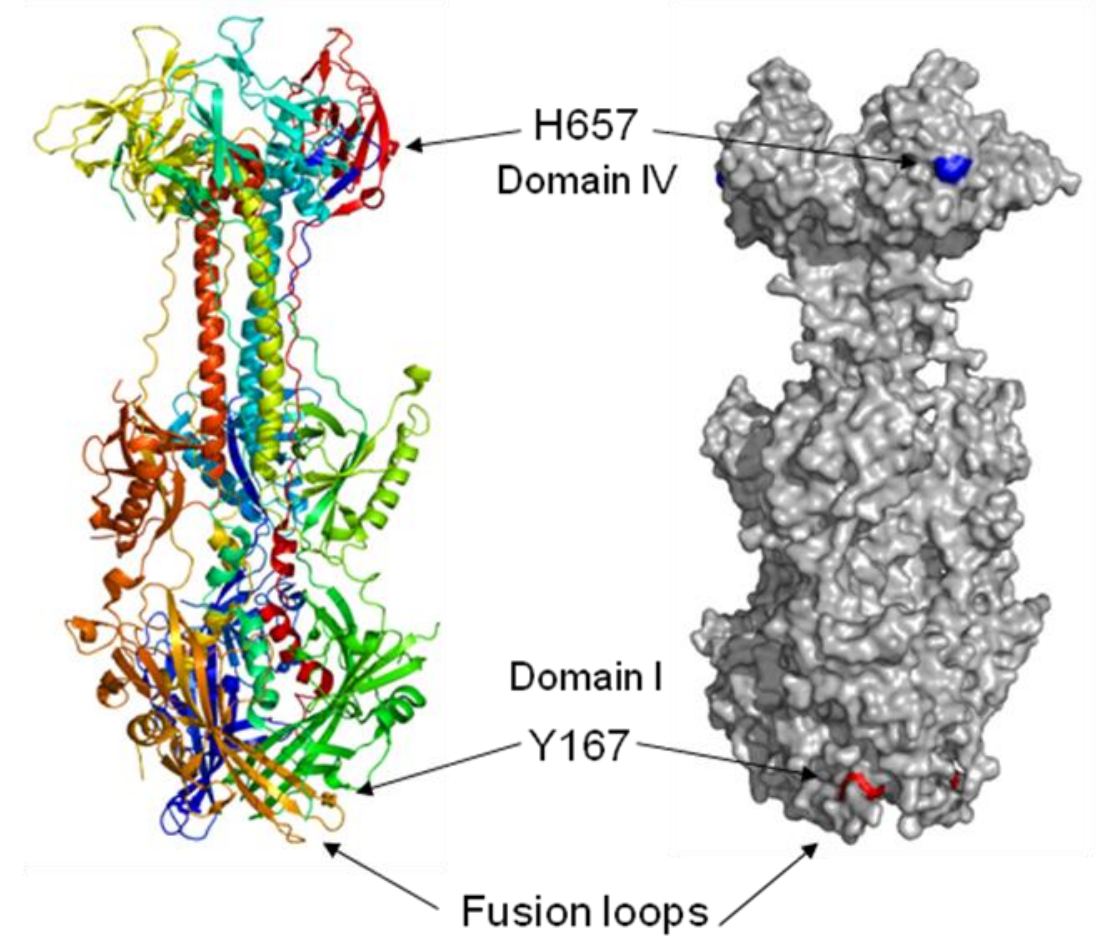

B)

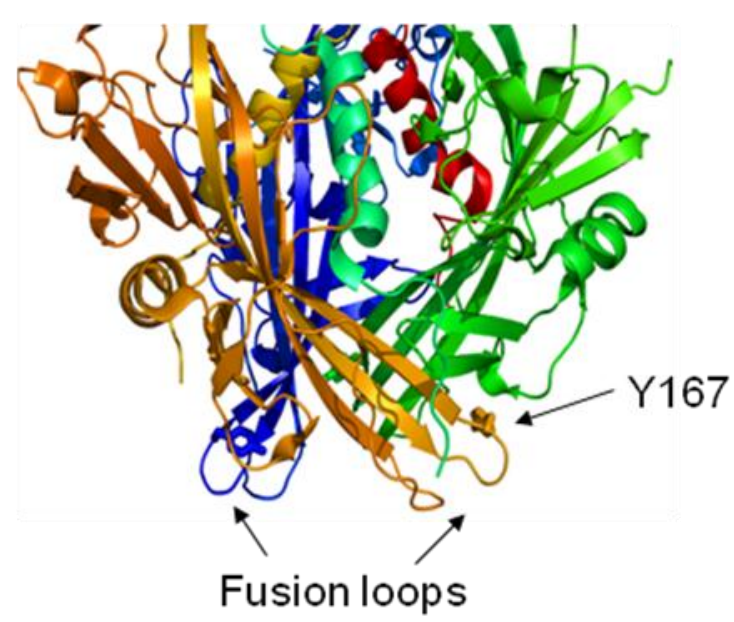

C) Domain IV

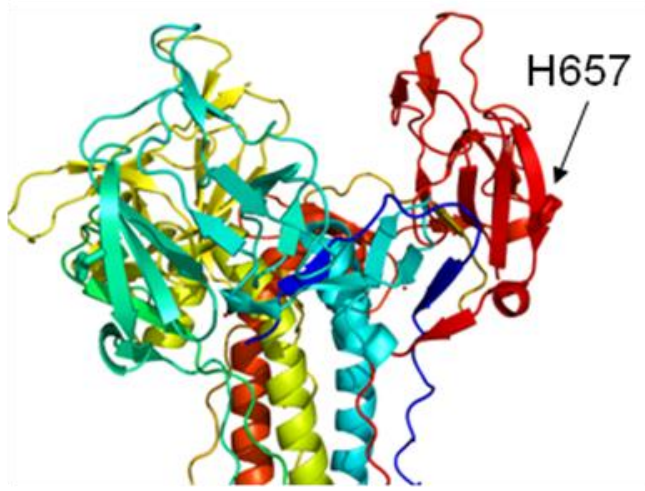

Figure 6: Location of the PrV gB FMDV epitope insertion sites mapped on the structure of HSV-1 gB. A) Ectodomains of HSV-1 gB form trimers. Each monomer is colored as blue, green or red (left panel), and a spacefilled model of the gB trimeric surface is shown on the right. $\mathrm{Y} 167$ and $\mathrm{H} 657$ are the HSV-1 residues that correspond to the insertion sites of the FMDV epitopes in PrV gB. HSV-1 gB fusion loops, which are the residues proposed to insert into the target membrane during fusion, are marked. B, C) Only domains I and IV, respectively, are shown for clarity, and insertion sites $\mathrm{Y} 167$ and $\mathrm{H} 657$ are labelled. Residue $\mathrm{Y} 167$, which would correspond to the N-term FMDV epitope insertion, seems less accessible than the fully exposed $\mathrm{H} 657$, which is analogous to the position where the C-term FMDV epitope was added. This suggests that the latter position might be a better insertion target. 